\title{
Teaching through Play: Using Video Games as a Platform to Teach about the Past
}

\author{
Krijn H.J. Boom ${ }^{*}$, Csilla E. Ariese ${ }^{\dagger \varsigma}$, \\ Bram van den Hout ${ }^{\ddagger}$, Angus A.A. Mol ${ }^{\star \varsigma}$ \\ and Aris Politopoulos ${ }^{\star}$ \\ ${ }^{\star}$ Leiden University \\ ${ }^{\dagger}$ University of Amsterdam

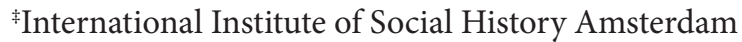 \\ ${ }^{\S}$ VALUE Foundation
}

\begin{abstract}
The video game market is a big part of the current popular media landscape and is growing rapidly. Developers of video games are keen to make use of a variety of historical pasts as this provides them with recognisable themes, settings or narrative frameworks. Video games can be seen as the manifestation of experiential learning theory: they provide a unique informal learning
\end{abstract}

How to cite this book chapter:

Boom, K. H. J., Ariese, C. E., van den Hout, B., Mol, A. A. A. and Politopoulos, A. 2020. Teaching through Play: Using Video Games as a Platform to Teach about the Past. In: Hageneuer, S. (ed.) Communicating the Past in the Digital Age: Proceedings of the International Conference on Digital Methods in Teaching and Learning in Archaeology (12-13 October 2018). Pp. 27-44. London: Ubiquity Press. DOI: https://doi.org/10.5334/bch.c. License: CC-BY 4.0 
environment in which their interactive nature allows for an immersive experience with which a deeper level of personal and historical learning can potentially be reached than in more formal settings. However, pasts incorporated in video games are mostly utilised to provide a fun experience in order to generate revenue. As more and more people depend on video games to teach them about the past, they often take the history presented in them for granted, relying on developers to tell an accurate story. Unmediated, players are prone to miss opportunities for critical engagement with the presented past, and can fall into the trap of presentism.

It is important for those teaching about the past to understand how video games work, and what their potential and impact are. Data-driven approaches allow us to explore what types of games are considered to be 'historical'. Our research shows that 206 million copies of games have been sold through Steam that were tagged as historical, and can be classified as strategy/top-down games, action-adventure narrative-driven games, or first-person action games. These types all have a reliance on some form of violence as central game mechanic, which needs to be taken into account when using video games as an education platform.

Through four case studies, we show that video games can function as a platform to teach about the past in a critical, yet fun way. Firstly, Twine can be used to stimulate critical and multi-linear thinking as it allows the user to create a narrative based on a branching structure instead of a linear one. Secondly, video games can be incorporated into formal classroom settings in order to illustrate certain complex theoretical concepts. Streaming, or creating videos about games that incorporate the past, can be a major avenue for content-focused teaching, as well as a way to reflect on video game pasts - the third case study. Lastly, our RoMeincraft case study shows that participants are not only taught something about Roman heritage but also able to increase their skills in communication and digital media. The goal of this chapter is to provide researchers with practical examples set within a solid theoretical framework of how video games can be implemented as a teaching tool.

\section{Keywords}

Experiential Learning Theory, Video Games, Experience, Impact, The Past

\section{Introduction}

As the video game market is ever expanding within the contemporary media landscape (ESA 2018a; 2018b; Shieber 2019), big-budget game studios, indie developers, social media influencers and other creatives design their versions of the past, purely or mostly, as entertainment products, where the focus is on making money through designing fun. This is problematic in the sense that such individuals and organisations (1) have not traditionally been and are frequently still not taken seriously in their role of shaping our collective 
understanding about the past, (2) are not primarily (or at all) concerned with teaching about the past and (3), more and more, the connection many people have with the past is partly or even primarily shaped by video games, including how they learn or teach others about it. ${ }^{1}$ Learning about the past through video games can and does take place in the context of formal education or in public heritage institutions (e.g. Koutsabasis 2017; McCall 2016), but the majority of experiences take place through unstructured, informal learning. As video games are still often considered to be 'neglected media', which 'exhibit strong popular appeal and economic relevance, contrasted by a lack of cultural prestige and scientific coverage' (Reichmuth \& Werning 2006: 47), not much is known yet about how they shape the ways 'players engage with and think about the past' (Metzger \& Paxton 2016: 532). Thus, it is all the more important to research how video games influence people's understanding and experience of the past in order to improve teaching approaches.

The goal of this chapter is to share some practical approaches, based on the experiences of the authors, of how to leverage video games as a platform to teach about the past. While learning theory in the context of video games is discussed to illustrate the necessity of teacher mediation, the focus lies on how teachers can implement video games in their teaching. ${ }^{2}$

We will first discuss some theoretical considerations, as video games are not created in a vacuum and their use for history teaching has many implications, both positive and negative. Secondly, we will consider what kind of pasts people (tend to) play outside of structured heritage or educational experiences. Thirdly, we will discuss four case studies illustrating how the authors of this chapter, who are all part of the VALUE Foundation, ${ }^{3}$ have employed video games for teaching purposes in different contexts.

1 The video game market is an ever-expanding giant in the contemporary media landscape. In 2018, video game revenue reached its latest peak of 43.8 billion US dollars, making it one of, if not the, largest grossing entity in the entertainment industry, far surpassing Hollywood figures. More importantly, 64\% of US households own a device that they use to play video games and $60 \%$ of Americans play video games daily (ESA 2018a; 2018b).

${ }^{2}$ What the impact is on learning, especially as realised upon the different target groups, their individual perceptions and cognitive processes, is a subject that is characterised by a lack of data sets from structured studies. As such, there is a disbalance between teaching experiences and a data-driven understanding of how we learn about the past through games; the authors feel this needs to be a much more pronounced aspect of future research in this field.

3 The VALUE Foundation 'aims to design, facilitate, and conduct worldwide research, development, and outreach on the crossroads of gaming and academia. Our approach is characterized by playfulness and accessibility.' It consists of six members: Csilla Ariese, Krijn Boom, Angus Mol, Aris Politopoulos, Bram van den Hout and Vincent Vandemeulebroucke. VALUE has three core focus areas: firstly, to organise knowledge activation and dissemination projects (e.g. the RoMeincraft project detailed below); secondly, to bring the gaming industry and knowledge institutions 


\section{Experiencing the past}

History and archaeology are fascinating subjects for video game developers: many video games revolve around historical settings, characters or ideas (Chapman 2016; Mol et al. 2017) and developers have many ways to 'deploy' the past, for instance to guide the game's narrative or to convey a sense of historical representation, but also to send (knowingly or unknowingly) a political message (e.g. Alexandra 2018) or to glorify a certain historical era (Metzger \& Paxton 2016).

On the one hand, it is a good thing that many video game developers embrace the past as a way to tell a good story - for example, online discussion forums for such games are often filled with players taking their game experiences as a way to discuss actual history and heritage with each other. The unique feature of video games is that they are interactive: players absorb a particular narrative while taking part at the same time, enabling players to experience a shift in their self-perception (Gilbert 2019: 111). In essence, video games are playful manifestations of experiential learning theory (ELT), which can be defined as 'the process whereby knowledge is created through the transformation of experience' (Kolb 1984: 23). In Gilbert's study, for example, students emphasised how playing and following stories made them experience the past and feel an immediate access to history and a sense of human connection to people in the past - both results contrasting with formal high-school learning (Gilbert 2019). Another core feature of video games is that their narratives can be based on non-linear storytelling. These branching structures allow players to change the course of the story, allowing for multiple directions and outcomes (Wolf 2001). While playing Assassin's Creed (AC) games, Gilbert's students indeed perceived these multiple perspectives in history, incorporated into the game by its developers. Importantly, this narrative structure allowed them to reflect upon historical events and characters and as such think differently about their understanding of both history and themselves (Gilbert 2019). The AC franchise is known for having strong narrative-driven stories, combining linear storytelling with branching structures. The last iterations of the franchise even include so-called 'Discovery Tours', providing players with a game mode purely focused on non-combat, educational aspects (Politopoulos et al. 2019). However, the past as incorporated in the AC games is still rather 'fixed.' Other video games, such as Sid Meier's Civilization (Civ), allow the player much more freedom in their play with the past. $\mathrm{Civ}$ is a strategy game which allows players to 'engage

closer together; and, thirdly, to conduct research on gaming and the use of gaming for research, outreach, and teaching. Most of VALUE's formal learning activities have focused on tertiary education. For more information: www.value-foundation.org.

${ }^{4}$ On 10 June 2019 a so-called Story Creator Mode was launched, allowing players to create and share their own stories in the AC-Odyssey universe. See: https:// assassinscreed.ubisoft.com/story-creator-mode/en-us. 
with past and present technological advances, social systems, and built heritage in a playful history that is closely analogous to but always slightly different from our own' (Mol, Politopoulos \& Ariese-Vandemeulebroucke 2017: 1; more about Civ below). Roberts wrote about the usefulness of this 'counterfactual history' for teaching purposes and concludes that his students, who could experiment with historical cause and effect in Civ, had an increased understanding of and interest in history (Roberts 2011). On the other end of the spectrum are games that allow players to create their own unique version, or representation, of history (see our case studies below for an example of this using Minecraft). What these brief examples show is that, in contrast to factual learning, video games allow players to experience the past by interacting with it as they go, deepening their understanding through reflection and experimentation. This is in line with ELT, which presupposes that learners need four different kinds of abilities: concrete experience abilities, reflective observation abilities, abstract conceptualisation abilities, and active experimentation (Kolb 1984). Video games inherently allow players access to all these abilities and act, as it were, as a learning conduit.

Although the above illustrates a quite positive picture of the potential that video games have in teaching about the past, there are certainly also some (known and lesser known) drawbacks. With the ever-growing video game market, students are increasingly positioned to combine their knowledge gained from popular culture media messages with that of formal academic teaching (Metzger \& Paxton 2016). In her study, Gilbert also noted that students missed opportunities for critical engagement with the past while playing video games and often took creative design decisions as historical facts, 'fully trusting the designers to present an unbiased view of history' (Gilbert 2019: 127). Furthermore, because of the immersive nature of video games, players are prone to presentism, trusting that their gameplay experience equals people's actual feelings at that time. Also, because video games are perceived as less valuable than more direct academic approaches to teaching about the past (Reichmuth \& Werning 2006), players might internalise that message too, giving less critical attention to the pasts they play. Students need guidance in these gameplay experiences. There is an 'absolute necessity for post-game reflective discussions to take place in order to disentangle factual and fictional elements and complement the learning experience' (Lynch, Mallon \& Connolly 2015: 35); formal teaching is still required in order for players to be able to critically analyse their more informal experiential learning experiences (Gilbert 2019).

\section{What pasts do people play?}

One important step in understanding how to teach about the past using games is to have an overview of the (types of) pasts that people play. There may be one, several or many games that intersect with the region, time period or theme one 
seeks to teach and it is good to add (a selection of) these to one's body of popular culture references. Beyond this direct connection, it is perhaps even more important to have a grasp of what types of narrative, audio-visual, mechanical and other features are found in games that are, broadly speaking, addressing the same pasts as we are. Obviously, playing some of these games is the best way to gain an understanding of the medium, although this is rather timeconsuming. There is now also a growing number of scholarly reviews discussing specific games and their relation to the past (e.g. McCall 2013; 2019; Mol, Politopoulos \& Ariese-Vandemeulebroucke 2017; Politopoulos et al. 2019). Beyond academic outlets, several blogs and YouTube series focus on the intersection of games and the past. ${ }^{5}$

Aside from learning about individual games, data-driven approaches allow us to explore this corpus on a larger scale. For example, there is SteamSpy, a web service that collects and allows access to data from Steam, the biggest digital distribution platform in the game industry. SteamSpy gives, among many other things, information on games that have been tagged by its users as 'historical', allowing for insights on playtime and numbers sold of individual games and the corpus as a whole. ${ }^{6}$ With SteamSpy data, it is also possible to explore the contents of these games, for example through tags, which are one- or two-word descriptive statements about a game by its players. Figure 1 is a visualisation that shows how tags in games (that are also tagged as 'historical') are connected to each other. The figure shows both the great diversity of features in this corpus, but also shows that certain tags are more frequently found together. Based on these stronger inter-tag relations it is possible to distil three subgroups of historical games: strategy/top-down games, action-adventure narrative-driven games, and first-person action games.

${ }^{5}$ Such as Shawn Graham's Electric Archaeology (https://electricarchaeology.ca), Andrew Reinhard's Archaeogaming (https://archaeogaming.com) - managed by Kaitlyn Kingsland since mid-2019, Dominik Schott's ArchaeoGames (https:// archaeogames.net) and VALUE's Interactive Pasts (http://interactivepasts.com).

6 'Historical' would be a relatively narrow term or scope in terms of an academic understanding of the past - i.e. taking place in historical times or a subject understood through the practice of history (Chapman 2016). Yet, the games that are actually tagged as 'historical' feature pasts that range from 'mythological' (Age of Mythology, Ensemble Studios, 2002) to 'postcolonial' (Tropico 5, Haemimont Games, 2014). This shows that, collectively, Steam users have a loose definition of 'historical', more in line with a more general conceptualisation of the past.

${ }^{7}$ Using the public SteamSpy API (Galyonkin, 2018), 342 different tags applied to 23,985 games on Steam (at the time of collection on 23 and 24 July 2018) were collected in a database, including not only if they were applied to a game but also how many times. This data provides the basis for a two-mode (game-to-tag) network, which can be transformed to either game-to-game or tag-to-tag similarity networks (Borgatti \& Everett 1997). In this case, the tag-to-tag network has been used to identify groupings within historical games, using Louvain Modularity network community detection, 


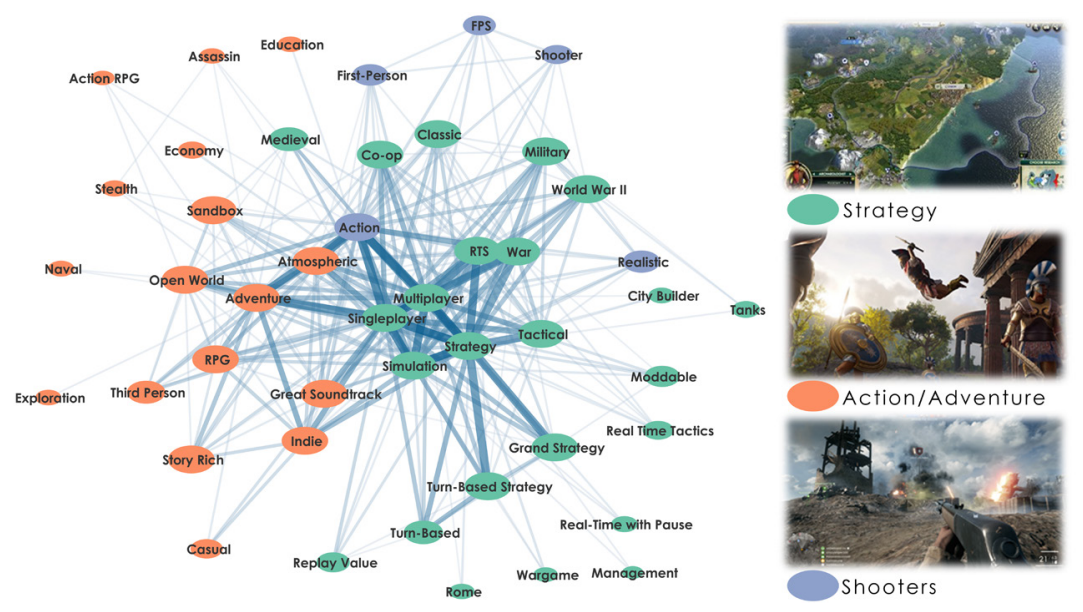

Figure 1: A network of tags applied to games on Steam by its users. These tags describe several aspects of features or themes that can be found in these games. The tags in this network all occur in games that have also been tagged as 'historical'. Width of links in this network indicates how often tags co-occur together (e.g. are found in the same game). The colour of nodes is based on a network community measure (see footnote) and show what family of historical games they belong to: strategy (image from Sid Meier's Civilization 6), action-adventure (image from Assassin's Creed: Odyssey), and shooters (image from Battlefield 1).

It falls outside the scope of this chapter to discuss these individual subgroups in depth, but an element uniting the corpus is the reliance on some form of violence as central play mechanic: from conquering other peoples in Sid Meier's Civilization series (Mol, Politopoulos \& Ariese-Vandemeulebroucke 2017) to the assassinations and swordplay of Assassin's Creed (Politopoulos et al. 2019), and the hyper-realistic gunplay in Battlefield. This is, of course, not unique to historical games: violent play has long been a core aspect of video games. Nor is the point here that this is actively harmful - studies on the psychological or social effects of violence in video games are, on the whole, inconclusive (e.g. Anderson, Gentile \& Buckley 2007; Przybylski \& Weinstein 2019). The point is rather that the vast majority of historical games, while showcasing a large set of features that may be important for players (evidenced by the diversity of tags applied to this corpus), end up with a relatively narrow and shallow experience of the past: only three groups within the corpus, all of them relying on violence

which measures the density of links inside network groups to links outside groups (Blondel et al. 2008). The groups that result from this could be conceptually understood as different members within the family of historical games (Mol 2019). 
as a mechanic to drive play. ${ }^{8}$ The violence of gaming pasts is something that needs to be taken into account when using video games as a teaching platform, and Gilbert's study is a prime example of this (Gilbert 2019). It also provides a challenge to archaeological, heritage and other academic professionals to contribute to or create playful experiences themselves that provide a more nuanced perspective on the past.

\section{Case studies}

We have sketched the enormous potential that video games have as learning material, based on their innate interactiveness, but also emphasised that this learning process still needs to be 'mediated' through teaching (Lynch, Mallon \& Connolly 2015: 35; Gilbert 2019). As a way to illustrate the teaching potential of video games, in this section we discuss practical examples of how the authors have approached the otherwise often narrow representations of the past in video games. Through four case studies, we showcase practical applications of using video games for teaching purposes in different contexts. They are chosen specifically because they present a wide variety of ways in which video games can be incorporated as (formal and informal) teaching material, as well as each providing an example of different target audiences.

The first case study covers Twine, a tool to create non-linear stories. VALUE organised several workshops on using Twine during our Interactive Past conferences. As such, this case study concerns academic conference delegates as main target audience. Our second case study comes from a formal educational setting: Aris Politopoulos uses game analogies to teach bachelor students about complex archaeological concepts. Thirdly, we discuss how streaming online allows the authors to reach and teach the general public about many historical and archaeological aspects using - and while playing - video games. Lastly, our final case study describes one of VALUE's public outreach activities RoMeincraft - aimed at the general public but particularly resonating with children aged six to 14 .

\section{Learning to tell stories with Twine}

Twine, an 'open source tool for telling interactive, non-linear stories,' ${ }^{\text {' }}$ allows anyone to write and create their own stories and - with some help from online tutorials and a helpful community - create games that range from simple to

${ }^{8}$ AC's combat-free Discovery Tour modes form an exception, although it can be argued whether they are still playful and interactive enough to be called games (Politopoulos et al. 2019).

9 Twine website: https://www.twinery.org. 
surprisingly complex designs, with images, audio, branching paths or even advanced gameplay mechanics with Twine macros, HTML, CSS codes and JavaScript. For the fields of archaeology and history (see Copplestone 2016), Twine is particularly interesting as a storytelling device because it works excellently for creating non-linear stories that allow for creative and multi-perspectival engagements with the past. ${ }^{10}$ For students or practitioners of the past, it can be a valuable - if conceptually challenging - exercise to design non-linear histories, particularly as most of their previous experience in storytelling will have been linear in the form of essays, papers or monographs.

VALUE has organised two- to five-hour workshop sessions at conferences in which predominantly academic educators and researchers are taught the basic workings of Twine. These short workshops encourage participants to explore the possibilities of Twine and consider whether they can use it for their own research dissemination or educational activities. Some of these participants continued with Twine after the workshop, either to finish their game in progress or to use Twine with their students. Longer workshops were organised as well (such as those during the two-day TIPC@Work in 2017 and the seven-day Game Jam during the Culture Arcade exhibition in 2018; see Figure 2), where more time was available for debate and reflection, as well as for invited game developers to share their expertise. ${ }^{11}$ Finally, Twine has also been used in BAlevel courses taught by Angus Mol. ${ }^{12}$

Having engaged roughly 140 scholars and students in creating historical stories in Twine, we can make some assessments of the educational value based on our observational evaluations and feedback from participants. Of course, writing your own story in Twine encourages independent and group research into the time period, person(s) or events which are involved in the story; thus, content knowledge is usually gained. Particularly within longer Twine workshops, independent (historical or archaeological) research skills are practised, mainly in the form of literature research, but also research into material culture and (online) museum collections. From a formal education perspective, what is most interesting is the extent to which writing a Twine story forces the writer to think through branching structures (Wolf 2001), alternative storylines and multiple endings, and cause and effect (Roberts 2011). Opposed to traditional

10 There are many great twines available for free or a suggested donation at https:// itch.io/games/tag-twine. For a good example of a Twine story that meaningfully incorporates the past, see McCall's Path of Honors (2018).

11 VALUE's Twine workshops were, among others, enriched by the presentations and attendance of game developers and designers Omar Gilani, Mata Haggis-Burridge, Hermen Hulst, Paweł Szyszka, Roy van der Schilden and Guillermo Vizcaíno, as well as archaeologists and Twine-ers Tara Copplestone and Jeremiah McCall.

12 Examples of Twines made by students include a biography of the early life of philosopher Ludwig Wittgenstein and a detective story based on two 1732 cases from the Old Bailey; see: dahi.lucdh.nl/twines2019. 


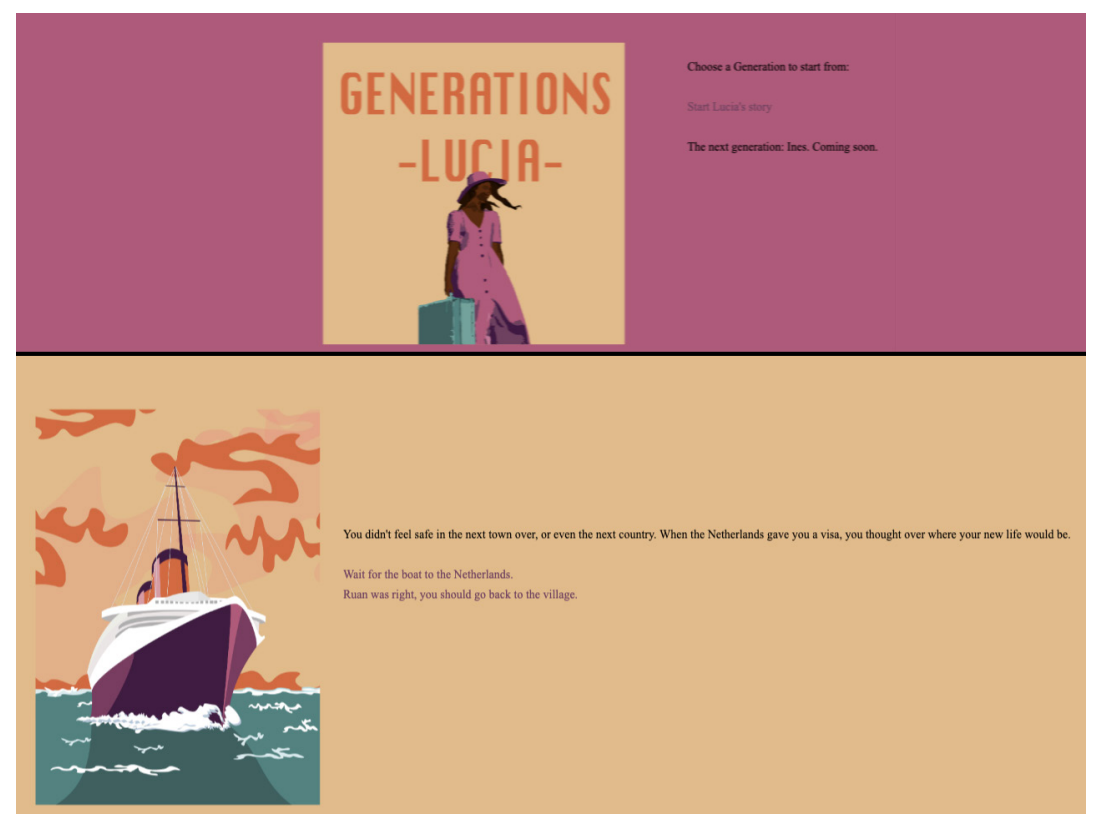

Figure 2: Two screenshots from the Twine game Generations: Lucia, made by Ana Barretto, Vera Grosskop and Phillip Morris during the Culture Arcade Game Jam, 2018.

linear scholarly writing, Twine can be valuable for interpreting fragments of the past to recreate or envision diverse possible scenarios.

\section{Game analogies in the classroom}

By using game analogies, we can teach difficult and complex terms through a medium that is popular, visually engaging and interactive, allowing students to have a hands-on approach - and recognisable examples - for theoretical and, often, abstract concepts. The examples presented in this chapter have been used for the purposes of teaching different courses on the archaeology of the ancient Near East by Aris Politopoulos. ${ }^{13}$

A first example of such an analogy is the historical and archaeological discussion around cities, city formation, and urban environments (e.g. Marcus \& Sabloff 2008). Discussion around ancient cities can often be too abstract for

${ }^{13}$ These courses include 'Archaeology of Empires', 'Early Cities and States of the Ancient Near East', and 'Early Complex Societies of the Ancient Near East', and were taught at Leiden University, Faculty of Archaeology from 2015/16-2018/19. 


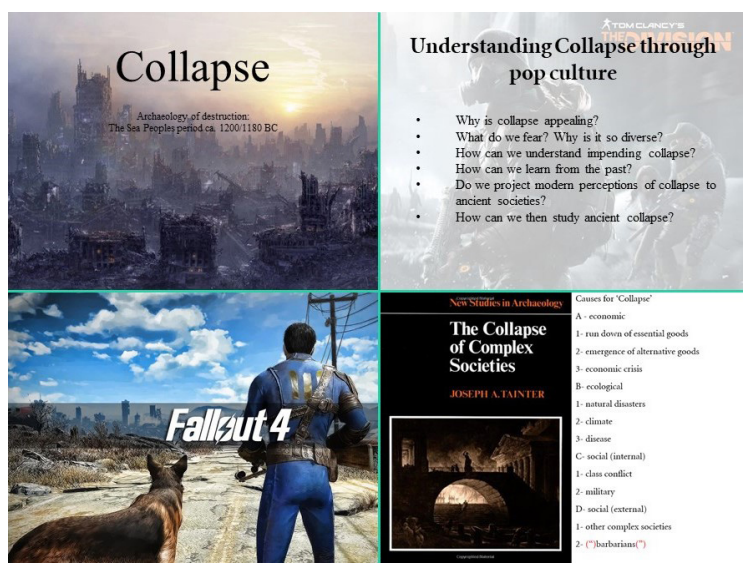

Figure 3: Slides from the course Early Cities and States of the Ancient Near East, discussing the concept of societal collapse as analogy.

students, while comparative examples from our everyday experiences of modern cities can be quite biased towards modern urban spatial conceptions. Games such as ANNO 1800 or Ancient Cities offer diverse and innovative approaches into the urban design of the past. Through these examples, it is possible to visualise, present, discuss and evaluate a number of different models regarding ancient urban design.

In a similar manner, video games can help us present models and conceptions of empire. Critically successful game series such as Age of Empires and the Civilization series have both shaped and been shaped by popular understanding of empires. They offer a good starting point to familiarise students with terminology, before delving deeper into specifics about the diverse theories of empires and imperialism (e.g. Burbank \& Cooper 2010).

Finally, video games offer the opportunity to discuss more contested concepts such as that of societal collapse. The topic of societal collapse has been both popular and controversial in archaeology and other sciences of the past (see most notably Tainter 1988). This has resulted in a convoluted and difficultto-grasp theoretical framework, which, while fascinating, can be particularly daunting. To solve this, we use examples of video games modelling different cases of collapse such as the Fallout ${ }^{14}$ series - societal collapse through war and nuclear destruction - or The Division series - societal collapse through the spread of disease (Figure 3). This allowed us to deconstruct some of the ideas around the concept of collapse, discuss them from a new perspective, and then

${ }^{14}$ For a discussion around collapse and Fallout 4 see VALUE's stream of the game: https://tinyurl.com/yykf7q39. 
proceed to the teaching of past instances of collapse, such as the late Bronze Age collapse.

The use of games as analogies has been very popular among students who participated in these courses. This was reflected in student evaluations, but also in specific comments, such as 'I appreciate the attempt of the lecturer to bring contemporary phenomena into the classroom' (student evaluation form, Early Cities and States course, 2016-2017).

\section{Streaming the past}

Video content is another great way to engage with a larger community, in particular with people who already play games. In some cases, YouTube channels like the popular-scientific History Respawned series, have gathered a massive number of followers who are both looking to be entertained and learn. Even if it is extremely difficult - requiring both a lot of hard work and a degree of luck - to reach such a level of popularity, creating video game-based video content is a great way to reach out beyond the classroom or conference rooms. Shawn Graham has, for example, created a quirky but fun YouTube video about video games and agent-based modelling ${ }^{15}$ and Andrew Reinhard has directed a small video report about archaeology in the No Man's Sky video game. ${ }^{16}$ Sophie Schmidt and Jan Wieners let their students create Let's Play videos, in which students critically comment on video games from an archaeological perspective in a short form video essay, as part of an archaeogaming course at the University of Cologne. ${ }^{17}$

Live streaming offers a different, and arguably even more interactive, way of creating content and engaging an audience than traditional online video formats (Taylor 2018). VALUE has been live streaming via the Twitch platform (https://twitch.tv/valuefnd) since 2016. With our 'Streaming the Past' series, we play and discuss a game together with a live audience. In these roughly two-hour episodes, we discuss specific (archaeological and historical) themes in relation to video games, such as 'Collapse and Fallout 4', 'Historical Agency and Assassin's Creed', and 'Violence in Human Nature and Far Cry: Primal. Furthermore, all content on Twitch can be live-streamed and recorded the same time (e.g. with open broadcasting software), which allows for the uploading of recordings of live streams to, for example, YouTube as videos on demand.

There are hurdles to creating live streams and other video content, however. First of all, in the current online video media landscape, discoverability of individual creators is extremely low. Indeed, to gain wider viewership and

${ }^{15}$ See: https://youtu.be/eCe5QEnoioI.

${ }^{16}$ See: https://www.youtube.com/watch?v=qORK8SUgM7E.

17 More information on this course can be found at: http://archaeoinformatics.net/ teaching-concepts-of-pre-history-in-computergames. 
popularity, supported by Twitch algorithms, it is necessary to stream regularly, often and extensively: to gain truly large numbers of viewers, daily streams of upwards of four hours are essential. In short, this is not a tool that will magically draw crowds of viewers (our average streaming audience numbers lie between five and 20 individuals), especially if 'production values' - what the videos sound and look like - are low. To create a live stream with solid production values requires the right hardware, software and set-up. Furthermore, there is an art to playing a game while maintaining an active and interesting mono- or dialogue simultaneously. That said, we consider live streams to be a major yet largely unexplored avenue for (video game-based and) contentfocused teaching as well as a way to reflect on video game pasts. What happens in our streams is both a deep dive into archaeological and heritage concepts and methods and a communal critical interaction with how games portray the past. In short, this is both a creative, performative and interactive way to play with and teach about the past.

\section{Teaching the past by playing RoMeincraft}

The blocky world of Minecraft - a game that could be called the digital version of LEGO - offers many opportunities to teach about the past in fun and creative ways. ${ }^{18}$ Starting with a pilot event in 2015, the VALUE Foundation has organised various types of events focused on (re)building heritage sites from around the world within Minecraft. ${ }^{19}$ The largest of these projects was RoMeincraft (Politopoulos et al., forthcoming). ${ }^{20}$ The project was designed for the province of South Holland to consist of 10 events, during which visitors and participants would, under our supervision as mediators, reconstruct the Limes (a Roman border in the Netherlands) and some of its heritage sites such as forts, harbours and watch towers. The project was later extended to other provinces and crossed the border into Belgium in 2019. These playful reconstructions were organised, prepared and guided by VALUE but largely executed by the visitors of the events, most of which took place at museums, as part of heritage festivals, or in public places (2017-2019) (see Figure 4). The Minecraft world in which these reconstructions took place was based on a digital reconstruction of the provincial landscape from Roman times (CE 200; based on height

${ }^{18}$ See projects by Colleen Morgan (https://colleen-morgan.com/2015/06/11/breaking-blocks-and-digging-holes-archaeology-minecraft) and Shawn Graham (https:// electricarchaeology.ca/tag/minecraft) as examples.

19 Similar projects have been organised elsewhere in the world, such as by the Creative Minds team for the DigIt festival in Scotland (McGraw, Reid \& Sanders 2017).

${ }^{20}$ RoMeincraft is a wordplay in Dutch, combining the title of the game with the Dutch word for Roman: 'Romein'. 


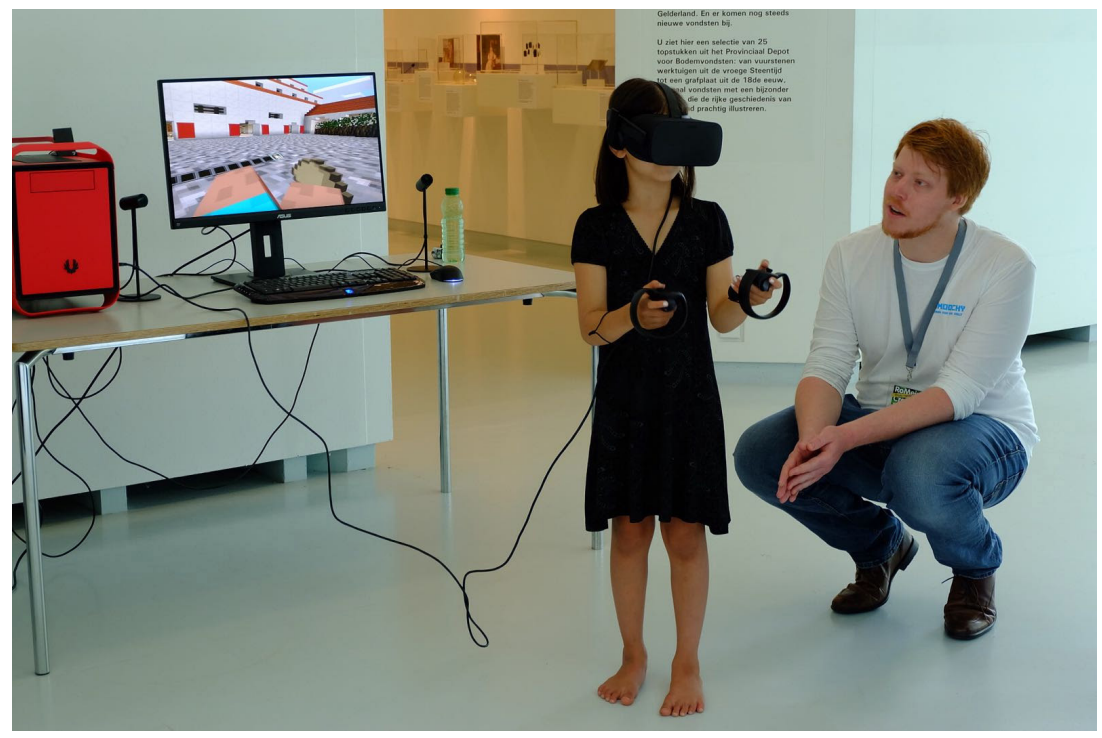

Figure 4: Participant of a RoMeincraft event explores the Minecraft reconstruction of Roman Nijmegen in virtual reality, guided by Bram van den Hout, Museum Het Valkhof. @ Maud Heldens.

maps); archaeological data in visual form such as site plans and cross-sections of buildings were collected in a booklet for referential purposes.

RoMeincraft events have managed to engage over a thousand participants (players and spectators) with Roman heritage. Generally speaking, players are mostly young children (aged around six to 14), although older children, teens, adults and seniors have also played. At the guidance of VALUE, play was always collaborative - not just with multiple computers connected to the same map but also in real life with family members sitting together at one computer - meaning that these events contributed to supporting social skills and interpersonal communication, between family members but also with strangers. It would often happen that children approached each other to ask for help with bigger building projects or they would go back and forth between the computers to consult with each other which material to use or how to design the building, while explaining the purpose of the structure they were working on. Collaboration was key, as players needed to be respectful of what others were building or had built or to engage in large-scale projects simultaneously together.

Mediation by VALUE members and other participants was important here: (grand)parents were often best placed to 'translate' the provided archaeological knowledge; children then interpreted this creatively into their building process. The ongoing, unstructured conversations between participants also often led to exchanges of knowledge about what would have been - or would 
not have been - accurate for Roman times. We noticed that many visitors both adults and children - had preconceived notions of what was, or was not, 'Roman'. For instance: yes, the Romans did have heated baths, but, no, they did not have rollercoasters. A core skill in archaeology, namely interpreting fragmentary remains such as foundations into full, detailed 3D structures, was inherently part of the creative RoMeincraft process and experientially learned: spatial skills and a consideration of the materiality of structural elements (i.e. selecting the right type of block) were combined. Finally, RoMeincraft also fostered some digital skills: general computer usage but even some 'coding' through cheats. The majority of our younger visitors were very experienced with Minecraft, and some engaged in 'counterplay' rather than contributing to the ongoing building projects. Engaging with Roman heritage in RoMeincraft, whether as a spectator or player, required constant mediation between actual past and digital present and an ongoing conversational knowledge exchange. RoMeincraft follows the principles of ELT, and provided an opportunity for players to learn from experience (Kolb 1984). Yet, while we have indications based on informal conversations and observations, quantitative and qualitative research needs to be undertaken to better understand the educational impact (Metzger \& Paxton 2016).

\section{Conclusion}

Video games that incorporate the past as part of their narrative, theme or setting provide a great opportunity space for experiential learning. Their inherently interactive character allows for an immersive experience and through this both a deeper and wider understanding of the played past. However, although more and more people are relying on video games to teach them about the past, video games' raison d'être is the generation of economic revenue. As such they often provide a relatively narrow and shallow experience of the past, which is framed in a way to make a gripping story or interesting gameplay, or simply to have fun. Oftentimes, these shallow experiences of the past are driven by violence. In order to make more use of video games as an educational platform, both in formal and informal settings, it is important to better understand the educational impact video games have on players, and to find opportunities in which interaction between the players and the past can be discussed or mediated in order for the latter to be more critically assessed. Through the presented case studies we have provided a number of playful opportunities in a wide variety of contexts and for different audiences. We have briefly showcased how pasts could be taught interactively, although research on learning and impact measurements remains necessary. As such, the chapter shows the practical applicability of video games for teaching purposes, illustrating through four selected case studies how a wide variety of audiences can be engaged through different games and particular mediated approaches. 


\section{References}

Alexandra, H. (2018). The Division 2 Is Political, Despite What Its Developers Say. [online] Kotaku. Available at: https://kotaku.com/the-division-2-ispolitical-despite-what-its-developer-1826776710 [Accessed 3 May 2019].

Anderson, C.A., Gentile, D.A., and Buckley, K.E. (2007). Violent Video Game Effects on Children and Adolescents: Theory, Research, and Public Policy, Oxford/New York: Oxford University Press.

Blondel, V.D., Guillaume, J., Lambiotte, R. and Lefebvre, E. (2008). Fast unfolding of communities in large networks. Journal of Statistical Mechanics: Theory and Experiment, 2008(10): P10008.

Borgatti, S.P. and Everett, M.G. (1997). Network analysis of 2-mode data. Social Networks, 19: 243-269.

Burbank, J. and Cooper, F. (2010). Empires in World History: Power and the Politics of Difference, Princeton, NJ: Princeton University Press.

Chapman, A. (2016). Digital Games as History: How Videogames Represent the Past and Offer Access to Historical Practice, New York: Routledge.

Copplestone, T. (2016). Twine for Archaeology Dummies: A Living Book about How to Make Things about and for Archaeology Using the Twine Engine. [online] GitBook. Available at: https://taracopplestone.gitbooks.io/twine4-archaeology-dummies/content [Accessed 25 April 2019].

ESA [Entertainment Software Association] (2018a). 2018 Sales, Demographic, and Usage Data: Essential Facts about the Computer and Video Game Industry. [pdf] Entertainment Software Association. Available at: http://www.theesa. com/wp-content/uploads/2018/05/EF2018_FINAL.pdf [Accessed 19 April 2019].

ESA (2018b). U.S Video Game Sales Reach Record-Breaking \$43.4 Billion in 2018. [online] Entertainment Software Association. Available at: http:// www.theesa.com/article/u-s-video-game-sales-reach-record-breaking-434-billion-2018 [Accessed 3 May 2019].

Galyonkin, S. (2018). Steam Spy API. [online] SteamSpy. Available at: https:// steamspy.com/api.php [Accessed 23 November 2018].

Gilbert, L. (2019). 'Assassin's Creed reminds us that history is human experience': Students' senses of empathy while playing a narrative video game. Theory \& Research in Social Education, 47: 108-137.

Kolb, D.A. (1984). Experiential Learning: Experience as the Source of Learning and Development, Englewood Cliffs, NJ: Prentice Hall.

Koutsabasis, P. (2017). Empirical evaluations of interactive systems in cultural heritage: A review. International Journal of Computational Methods in Heritage Science, 1: 100-122.

Lynch, R., Mallon, B. and Connolly, C. (2015). The pedagogical application of alternate reality games: Using game-based learning to revisit history. International Journal of Game-Based Learning, 5: 18-38. 
McCall, J. (2013). Playing with the Past: Digital Games and the Simulation of History, London: Bloomsbury Academic.

McCall, J. (2016). Teaching history with digital historical games: An introduction to the field and best practices. Simulation \& Gaming, 47: 517-542.

McCall, J. (2018). Path of Honors: Towards a Model for Interactive History Texts with Twine, DOI: https://doi.org/10.22215/epoiesen/2017.16.

McCall, J. (2019). Playing with the past: History and video games (and why it might matter). Journal of Geek Studies, 6(1): 29-48.

McGraw, J., Reid, S. and Sanders, J. (2017). Crafting the past: Unlocking new audiences. In: A.A.A. Mol, C.E. Ariese-Vandemeulebroucke, K.H.J. Boom and A. Politopoulos, eds, The Interactive Past: Archaeology, Heritage, and Video Games, Leiden: Sidestone Press, pp. 167-184.

Marcus, J. and Sabloff, J.A. (2008). The Ancient City: New Perspectives on Urbanism in the Old and New World, Santa Fe, NM: School for Advanced Research.

Metzger, S.A. and Paxton, R.J. (2016). Gaming history: A framework for what video games teach about the past. Theory \& Research in Social Education, 44: 532-564.

Mol, A.A.A. (2019). Gaming Genres: Using Crowd-Sourced Tags to Explore Family Resemblances in Steam Games. Digital Humanities Conference 2019.

Mol, A.A.A., Ariese-Vandemeulebroucke, C.E., Boom, K.H.J. and Politopoulos, A. (2017). The Interactive Past: Archaeology, Heritage, and Video Games, Leiden: Sidestone Press.

Mol, A.A.A., Politopoulos, A. and Ariese-Vandemeulebroucke, C.E. (2017). From the Stone Age to the Information Age: History and Heritage in Sid Meier's Civilization VI. Advances in Archaeological Practice, 5(2): 214-219.

Politopoulos, A., Mol, A.A.A., Boom, K.H.J. and Ariese, C.E. (2019). History is our playground: Action and authenticity in Assassin's Creed: Odyssey, Advances in Archaeological Practice, 7(3): 317-323.

Politopoulos, A., Ariese, C.E., Boom, K.H.J. and Mol, A.A.A. (forthcoming). Romans and rollercoasters: Scholarship in the digital playground. Journal of Computer Applications in Archaeology.

Przybylski, A.K. and Weinstein, M. (2019). Violent video game engagement is not associated with adolescents' aggressive behaviour: Evidence from a registered report. Royal Society Open Science, 6(2): 171474.

Reichmuth, P. and Werning, S. (2006). Pixel pashas, digital djinns. ISIM Review, 18: 46-47.

Roberts, S.L. (2011). Using counterfactual history to enhance students' historical understanding. The Social Studies, 102: 117-123.

Shieber, J. (2019). Video Game Revenue Tops $\$ 43$ Billion in 2018, an 18\% Jump from 2017. [online] Techcrunch. Available at: https://techcrunch. com/2019/01/22/video-game-revenue-tops-43-billion-in-2018-an18-jump-from-2017 [Accessed 3 May 2019]. 
Tainter, J.A. (1988). The Collapse of Complex Societies, Cambridge: Cambridge University Press.

Taylor, T.L. (2018). Watch Me Play: Twitch and the Rise of Game Live Streaming, Princeton, NJ: Princeton University Press.

Wolf, M.J.P. (2001). Narrative in the video game. In: M.J.P. Wolf, ed., The Medium of the Video Game, Austin, TX: University of Texas Press, pp. 94-111.

\section{Ludography}

Age of Empires series (1997-2018). Ensemble Studios, Relic Entertainment. Microsoft Game Studios. [Multiple platforms]. Age of Mythology (2002). Ensemble Studios. Microsoft. [PC and MAC]. Ancient Cities (In development). Uncasual Games. [PC]. ANNO 1800 (2019). Blue Byte. Ubisoft. [PC]. Assassin's Creed series (2007-2018). Blue Byte, Gameloft, Ubisoft Montréal, Ubisoft Paris, Ubisoft Quebec, Ubisoft Sofia. Ubisoft. [Multiple platforms]. Battlefield series (2002-2018). EA Digital Illusions CE, Visceral Games. Electronic Arts. [Multiple platforms].

Civilization series (1991-2016). MicroProse \& Firaxis Games. MicroProse, Activision, Infogrames Entertainment \& $2 \mathrm{~K}$ Games. [Multiple platforms]. Fallout series (1997-2018). Interplay Entertainment, Black Isle Studios \& Bethesda Game Studios. Interplay Entertainment \& Bethesda Softworks. [Multiple platforms].

Minecraft (2011). Mojang. Mojang \& Microsoft. [Multiple platforms].

The Division series (2016-2019). Massive Entertainment. Ubisoft. [Multiple platforms].

Tropico 5 (2014). Haemimont Games. Kalypso Media \& Square Enix. [Multiple platforms]. 